\title{
STUDI AKTIVITAS ANTIOKSIDAN CUKA BERBASIS BUAH ANGGUR BALI (Vitis vinifera) UTUH DAN TANPA KULIT
}

\author{
ANTIOXIDANT ACTIVITY OF VINEGAR BASED BALI GRAPES (Vitis vinifera)
}

\author{
Elok Zubaidah ${ }^{1)}$ Christina Veronica ${ }^{2)}$ \\ ${ }^{1)}$ Staf Program Ilmu dan Teknologi Pangan , FTP - Universitas Brawijaya, Malang \\ 2), Alumni Program Ilmu dan Teknologi Pangan, FTP - Universitas Brawijaya, Malang \\ Email: elzoeba@yahoo.com
}

\begin{abstract}
Balinese Grapes (Vitis vinifera) is less in demand by consumers for consumption directly because it tastes sour. Some of the content of compounds in Balinese grapes has potential as an antioxidant such as vitamin $C$, flavonoids, and polyphenols. Processing bali wine into vinegar fruit is expected to be produced products that have high health effects. The purpose of this study was to determine the effect of removing and non fruit skin and the addition of water to the antioxidant activity of wine vinegar Bali. This study used a randomized block design (RBD) with 2 factors. The best treatment was obtained in Bali grape vinegar treatment the proportion of whole fruit and fruit : water 1:1, has a chemical parameters such as total acid $5.74 \%$, pH 3.27 and $59.49 \%$.
\end{abstract}

Keywords: balinese grapes, fruit skin, vinegar

\section{ABSTRAK}

Anggur Bali (Vitis vinifera) selama ini kurang diminati oleh konsumen karena rasanya yang sangat asam. Beberapa kandungan senyawa dalam buah anggur Bali memiliki potensi sebagai antioksidan antara lain vitamin $\mathrm{C}$, flavonoid, dan polifenol. Pengolahan anggur bali menjadi cuka buah diharapkan akan dihasilkan produk yang memiliki efek kesehatan yang tinggi. Tujuan penelitian ini adalah untuk mengetahui pengaruh kulit buah dan penambahan air terhadap aktivitas antioksidan cuka anggur Bali. Penelitian ini menggunakan Rancangan Acak Kelompok (RAK) dengan 2 faktor. Faktor pertama adalah perlakuan anggur utuh dan anggur kupas. Sedangkan faktor kedua adalah proporsi buah: air (1:1, 1:2, 1:3). Data yang diperoleh dianalisis dengan ANOVA. Perlakuan terbaik cuka anggur Bali diperoleh pada perlakuan buah utuh dan proporsi buah:air 1:1, memiliki parameter kimia seperti total asam 5,74\%, pH 3,27 dan aktivitas antioksidan 59,49\%.

Kata Kunci : anggur bali, antioksidan, cuka, kulit buah

\section{PENDAHULUAN}

Buah anggur Bali (Vitis vinifera) banyak ditanam di daerah dataran rendah seperti di daerah Jawa Timur (Probolinggo, Pasuruan, Situbondo), Bali dan Kupang (NTT). Buah Anggur Bali memiliki ciri-ciri berwarna biru kehitamanan, kulit yang tebal dan rasanya yang asam bercampur kelat. Kulit buah anggur banyak mengandung antosianin. Antosianin memiliki fungsi fisiologis yaitu sebagai antioksidan, antikanker dan perlindungan terhadap kerusakan hati. Selain antosianin, kulit buah anggur juga mengandung resveratrol dan flavonoids lain seperti katekin, quercetin dan prosianidin. Selain itu anggur juga mengandung sejumlah vitamin yaitu vitamin C, B6, K dan B1. Kandungan antioksidan dalam anggur tersebut sudah diyakini oleh kalangan luas sebagai pelindung sel dari radikal bebas (Anonymous ${ }^{\mathrm{a}}, 2010$ ).
Buah Anggur Bali selama ini kurang diminati oleh konsumen untuk dikonsumsi secara langsung. Oleh sebab itu, diperlukan alternatif pengolahan lanjutan untuk meningkatkan nilai ekonomis dari Buah Anggur Bali. Pemanfaatan anggur Bali dapat dilakukan dengan pengolahan produk fermentasi seperti cuka (Vinegar), sehingga produk ini mempunyai nilai ekonomis yang lebih tinggi dan diharapkan dapat menjadi salah satu alternatif pangan fungsional. Kelebihan dari produk cuka sendiri adalah kadar alkoholnya yang jauh lebih rendah dari produk wine dan menurut Yatni (2008), cuka memiliki daya simpan yang lama disebabkan kandungan asam asetatnya. Sebanyak $0,1 \%$ asam asetat dapat menghambat pertumbuhan bakteri pembentuk spora penyebab keracunan makanan dan $0,3 \%$ asam asetat dapat mencegah kapang penghasil metoksin. Selain itu karena kondisinya yang asam, cuka tidak memerlukan bahan pengawet dan penyimpanan pada suhu rendah. 
Cuka merupakan cairan yang dibuat dari berbagai bahan yang bergula atau berpati melalui fermentasi alkohol yang diikuti dengan fermentasi asetat. Produk ini merupakan suatu larutan asam asetat dalam air yang mengandung cita rasa, zat warna dan substansi yang terekstrak, asam buah, garamgaram organik dari buah yang berbeda-beda sesuai dengan asalnya (Pragana, 2010).

Cuka anggur atau yang biasa disebut dengan "wine vinegar" sudah banyak diproduksi di dalam dan luar negri. Namun belum ada penelitian tentang aktivitas antioksidan yang terdapat pada cuka anggur Bali menggunakan sari buah anggur Bali beserta kulitnya dan sari buah anggur Bali tanpa kulit (sudah dikupas). Kulit buah anggur mengandung senyawa antioksidan yang tinggi. Oleh sebab itu, perlu penelitian tentang pengaruh kulit buah dan proporsi penambahan air.

\section{METODE PENELITIAN}

\section{Bahan dan Alat}

Anggur Bali didapatkan dari Probolinggo, Jawa Timur. Kultur Acetobacter acetii, Saccharomyces cerevisiae, pepton, glukosa, ekstrak khamir, media NA, dan media NB didapatkan dari Laboratorium Mikrobiologi Pangan, Jurusan Teknologi hasil Pertanian, Fakultas Teknologi Pertanian, Universitas Brawijaya.

Seperangkat fermentor (botol, selang plastik, malam, dan gelas), aerator merk Amara, katup pengatur udara, timbangan analitik, erlenmeyer $250 \mathrm{~mL}, 500 \mathrm{~mL}$, autoklaf tipe HL36AE, blender merk Philips, spektrofotometer merk UNICO UV-2100), Laminar Air Flow (LAF), pipet mikro 10$100 \mu \mathrm{L}, 200-1000 \mu \mathrm{L}$, vortex (vortex mixer model VM-2000).

\section{Tahapan Penelitian}

\section{Pembuatan Inokulum Acetobacter acetii}

Acetobacter acetii biakan murni yang berumur 48 jam dilarutkan dalam media aktivasi cair sebanyak $10 \mathrm{ml}$ dalam tabung reaksi dengan menggunakan jarum ose 2-3 ose setiap $10 \mathrm{ml}$ secara aseptis kemudian diinkubasi selama 48 jam pada suhu $37^{\circ} \mathrm{C}$. Kemudian Acetobacter acetii biakan murni tersebut dipindahkan kedalam erlenmeyer yang berisi media aktivasi sebanyak $100 \mathrm{ml}$ secara aseptis, diinkubasi 48 jam pada suhu $37^{\circ} \mathrm{C}$. Sebanyak $10 \%$ starter dalam media cair aktivasi diinokulasi dalam filtrat beralkohol hasil fermentasi alkoholik dan diinkubasi selama 48 jam pada suhu $37^{\circ} \mathrm{C}$ kemudian digunakan sebagai inokulum.

\section{Fermentasi Alkohol}

Buah anggur Bali yang telah matang dihilangkan batangnya dan dicuci dengan air sampai bersih dan ditimbang, sebagian dikupas kulitnya, dibuang ampasnya lalu buah yang sudah dikupas ditimbang. Ditambahkan air masing-masing dengan perbandingan buah:air sebesar 1:1, 1:2 dan 1:3 (b/v), kemudian dihancurkan dengan blender selama 1 menit hingga diperoleh bubur buah. Kemudian bubur buah anggur Bali disaring dengan kain saring. Lalu ditambahan sukrosa sebanyak $12,5 \%$ dan diamonium hidrogen phosphat $0,2 \%(\mathrm{~b} / \mathrm{v})$. Sari buah anggur Bali dianalisa total asam, total gula, $\mathrm{pH}$, total fenol dan aktivitas antioksidan. Sari buah anggur Bali dipasteurisasi pada suhu $65^{\circ} \mathrm{C}$ selama 30 menit kemudian dimasukkan dalam botolbotol fermentor. Setelah dingin ditambahkan inokulum Saccharomyces cerevisiae sebanyak 5\% (v/v) dan dilakukan fermentasi selama 9 hari pada suhu kamar dalam kondisi anaerob. Sari anggur Bali yang beralkohol yang telah dihasilkan dianalisa kadar alkohol, total asam, $\mathrm{pH}$, total gula, total fenol dan aktivitas antioksidan. Kemudian dipasteurisasi selama 30 menit pada suhu $65^{\circ} \mathrm{C}$ untuk menghentikan fermentasi alkohol.

\section{Fermentasi Asetat}

Sari anggur Bali beralkohol setelah dipasteurisasi didinginkan, kemudian ditambahkan inokulum Acetobacter acetii sebanyak 20\% (v/v) dan difermentasi 3 minggu dengan aerasi 0,07 vvm. Penentuan kecepatan aerasi dilakukan dengan menghitung udara persatuan waktu untuk volume larutan pada medium yang akan difermentasi. Pada kecepatan aerasi 0,07 vvm berarti untuk medium fermentasi 1L maka dalam 1 menit volume udara yang dialirkan 
sebesar $70 \mathrm{~mL}$. Kemudian difermentasi selama 3 minggu. Setelah fermentasi selesai dilakukan penyaringan dan dipasteurisasi untuk menghentikan fermentasi asetat. Cuka anggur Bali dihasilkan kemudian dianalisa total gula, kadar alkohol, total asam, $\mathrm{pH}$, total fenol dan aktivitas antioksidan.

\section{Rancangan Percobaan}

Penelitian ini menggunakan Rancangan Acak Kelompok (RAK) dengan 2 faktor. Faktor pertama adalah perlakuan perbandingan antara anggur Bali utuh dan anggur Bali kupas. Sedangkan faktor kedua adalah proporsi buah: air (1:1, 1:2, 1:3). Masing-masing perlakuan dilakukan 3 kali ulangan.

\section{HASIL DAN PEMBAHASAN}

Tabel 1. Analisa Awal Sari Buah Anggur

\begin{tabular}{ccccccc}
\hline \multicolumn{2}{c}{ Perlakuan } & & & & Total \\
Buah & $\begin{array}{c}\text { Propor } \\
\text { si } \\
\text { Buah: } \\
\text { Air }\end{array}$ & $\begin{array}{c}\text { Total } \\
\text { Asam } \\
(\%)\end{array}$ & $\begin{array}{c}\text { Total } \\
\text { Gula } \\
(\%)\end{array}$ & $\begin{array}{c}\text { Aktivi } \\
\text { tas }\end{array}$ \\
& & & & & $\begin{array}{c}\text { fenol } \\
(\mathrm{ppm}\end{array}$ & $\begin{array}{c}\text { Antiok } \\
\text { sidan } \\
(\%)\end{array}$ \\
\hline \multirow{2}{*}{ Utuh } & $1: 1$ & 1,56 & 16,40 & 4,43 & 632,2 & 73,42 \\
& $1: 2$ & 1,32 & 14,83 & 4,80 & 607,3 & 64,86 \\
& $1: 3$ & 1,08 & 13,17 & 5,06 & 541,0 & 55,60 \\
\hline \multirow{2}{*}{ Ku } & $1: 1$ & 1,44 & 15,23 & 4,35 & 562,3 & 66,78 \\
pas & $1: 2$ & 1,2 & 14,00 & 4,70 & 531,9 & 55,15 \\
& $1: 3$ & 0,96 & 13,37 & 5,31 & 482,6 & 48,00 \\
\hline
\end{tabular}

Berdasarkan hasil analisa diperoleh nilai $\mathrm{pH}$ awal dari sari buah anggur berkisar antara 4,35-5,31. Fermentasi alkohol dapat berlangsung dalam kisaran $\mathrm{pH}$ tersebut karena menurut Fardiaz (1992) pH optimum Saccharomyces cerevisiae untuk menghasilkan alkohol adalah 4-5. Total asam sari buah anggur berkisar antara 0,96\% 1,56\%. Menurut Anugoro (2011), anggur banyak mengandung asam tartrat dan asam amalat dan asam-asam organik lainnya, hal inilah yang mempengaruhi tingkat keasaman dari sari buah anggur.

Total gula pada sari buah setelah dilakukan penambahan sukrosa berkisar antara 13,37-16,40\%. Analisa total gula awal dilakukan untuk mengetahui jumlah total gula yang terkandung dalam sari buah anggur. Hasil analisa total fenol pada sari buah anggur diperoleh sekitar 48,26-63,22.
Total fenol tersebut dipengaruhi oleh senyawa antosianin, menurut Hahlbrock (1981) antosianin memberikan pigmen warna merah, biru dan ungu. Hasil analisa aktivitas antioksidan sari buah anggur diperoleh sekitar 48,00 - 73,42\%. Menurut Anugoro (2011), beberapa kandungan senyawa dalam buah anggur Bali yang memiliki potensi antioksidan antara lain vitamin $\mathrm{C}$, flavonoid, dan polifenol. Berdasarkan hasil analisa, dapat dilihat bahwa rerata sari buah anggur yang utuh memiliki nilai total fenol dan aktivitas antioksidan yang lebih tinggi dibandingkan sari buah yang buahnya sudah dikupas. Hal ini dikarenakan pada kulit buah terdapat banyak kandungan flavonoid.

\section{Total Gula Sari Buah Anggur Bali Beralkohol}

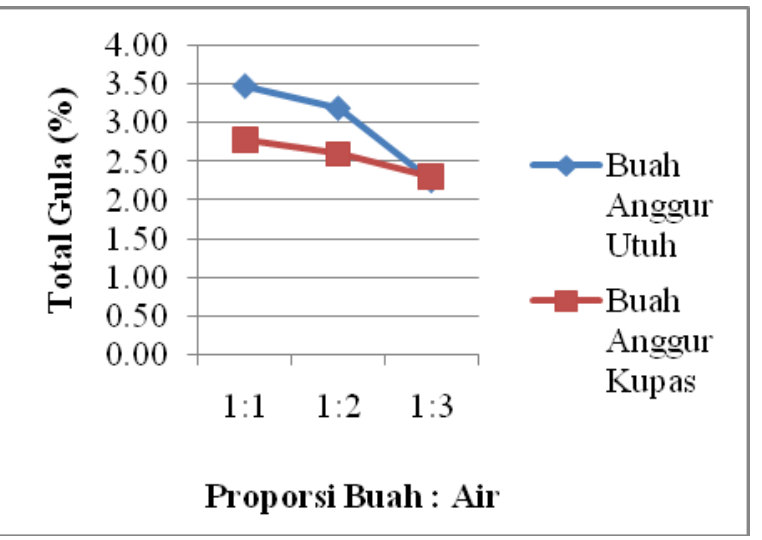

Gambar 1. Pengaruh Faktor Buah Utuh dan Buah Kupas serta Proporsi Buah : Air terhadap Total Gula pada Sari Buah Anggur Bali Beralkohol

Gambar 1 menunjukkan bahwa nilai total gula akibat faktor buah utuh dan buah kupas serta proporsi buah:air berkisar antara 2,27 - 3,49\%. Semakin tinggi proporsi buah:air mengakibatkan total gula alkohol mengalami penurunan sedangkan perlakuan buah utuh sebagai bahan baku menghasilkan tota gula yang lebih tinggi dibandingkan dengan perlakuan dengan menggunakan buah kupas. Total gula mengalami penurunan, hal ini terjadi karena gula telah dimanfaatkan oleh Saccharomyces cerevisiae dalam proses fermentasi. Gula tersebut dimanfaatkan oleh khamir untuk membentuk alkohol dan gas $\mathrm{CO}_{2}$ Total gula akhir yang terbesar diperoleh pada perlakuan 1:1 karena pada total gula awal sebelum fermentasi juga tinggi yaitu 
sebesar 16,40\%. Menurut Wood (1998), gula optimum bagi Saccharomyces cerevisiae adalah sebesar $10-15 \%$.

\section{Kadar Alkohol}

Pada proses fermentasi

Saccharomyces cerevisiae memecah substrat berupa gula menjadi alkohol. Pengaruh proporsi buah:air dan perlakuan buah utuh serta buah kupas dapat dilihat pada Tabel 2.

Pada Tabel 2 menunjukkan pada perlakuan proporsi buah : air 1:3 memiliki kadar alkohol yang paling tinggi. Hal ini terjadi diduga karena pengenceran mengurangi tingkat kepekatan dari sari buah sebagai medium awal fermentasi. Menurut Frobisher (1962) dalam Maharani (2011), semakin tinggi kadar gula maka semakin besar tekanan osmosis terhadap sel. Kadar alkohol yang dihasilkan pada masing-masing perlakuan sudah cukup baik untuk selanjutnya diubah menjadi asam asetat. Menurut Cirlini (2008), untuk menghasilkan cuka anggur dengan kualitas yang baik diperlukan kadar alkohol sebesar $8 \%$. Sedangkan menurut Hotmaka dalam Zubaidah (2010) kadar alkohol yang baik digunakan sebagai substrat dalam fermentasi asam asetat sebesar 5-7\%.

Tabel 2. Kadar Alkohol Sari Buah beralkohol akibat Proporsi Buah:Air dan Perlakuan Buah Utuh serta Buah Kupas.

\begin{tabular}{|c|c|c|}
\hline \multicolumn{2}{|c|}{ Perlakuan } & \multirow{2}{*}{$\begin{array}{c}\text { Kadar } \\
\text { Alkohol }(\%)\end{array}$} \\
\hline $\begin{array}{c}\text { Buah } \\
\text { Anggur }\end{array}$ & $\begin{array}{l}\text { Proporsi } \\
\text { Buah:Air }\end{array}$ & \\
\hline \multirow{3}{*}{ Utuh } & $1: 1$ & 7,9 \\
\hline & $1: 2$ & 9,25 \\
\hline & $1: 3$ & 10,28 \\
\hline \multirow{3}{*}{ Kupas } & $1: 1$ & 6,34 \\
\hline & $1: 2$ & 8,02 \\
\hline & $1: 3$ & 9,91 \\
\hline
\end{tabular}

\section{Nilai pH Sari Buah Anggur Bali Beralkohol}

Nilai pH merupakan salah satu parameter penting dalam pembuatan cuka. Pada fermentasi alkohol ini nantinya akan terjadi perombakan glukosa menjadi alkohol dan gas $\mathrm{CO}_{2}$ selain itu akan terjadi juga perubahan nilai $\mathrm{pH}$. Rerata nilai $\mathrm{pH}$ sari buah beralkohol akibat faktor proporsi buah:air dan buah utuh : buah kupas dapat dilihat pada Gambar 2.

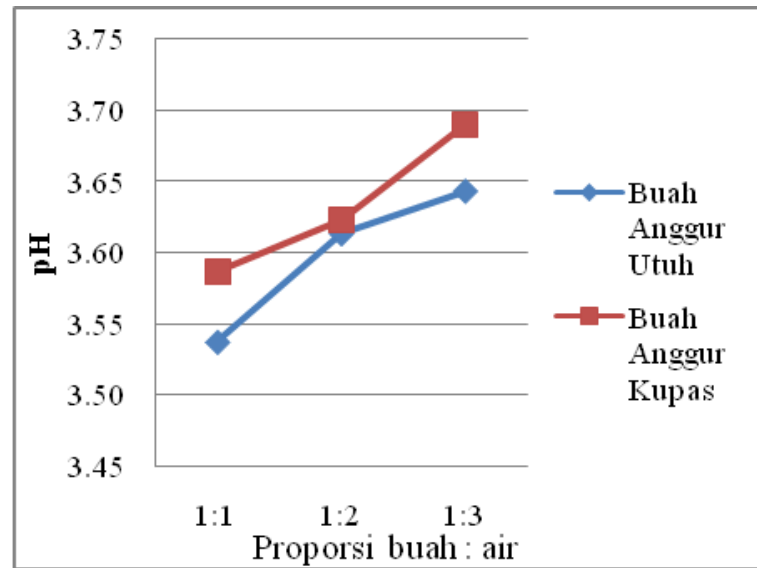

Gambar 2. Pengaruh Proporsi Buah:Air dan Buah Utuh serta Buah Kupas terhadap Rerata $\mathrm{pH}$ pada Sari Buah Anggur Beralkohol

Berdasarkan Gambar 2 menunjukkan bahwa nilai $\mathrm{pH}$ akibat faktor proporsi buah:air dan buah utuh serta buah kupas berkisar antara 3,54-3,69. Menurut Wignyanto (2001), perubahan $\mathrm{pH}$ dalam fermentasi disebabkan karena dalam aktivitasnya sel khamir selain menghasilkan etanol sebagai metabolit primer juga menghasilkan asam-asam organik seperti asam malat, asam tartarat, asam sitrat, asam asetat, asam butirat dan asam propionat sebagai hasil sampingan.

Total Asam Sari Buah Anggur Bali Beralkohol

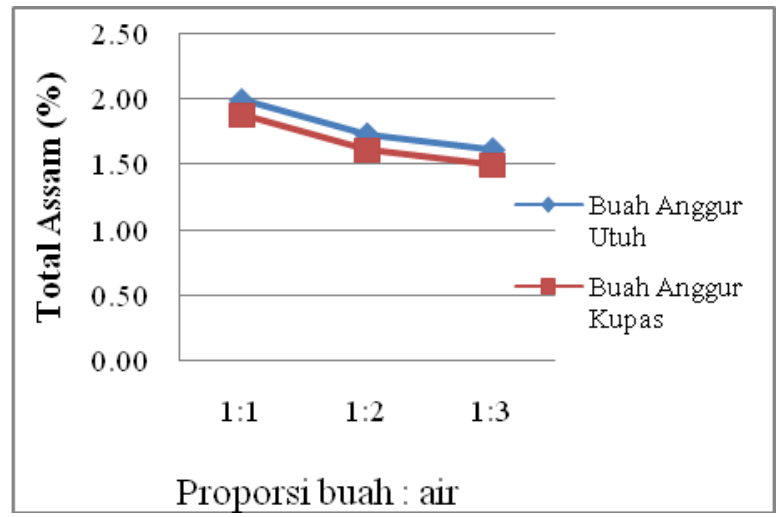

Gambar 3. Pengaruh Proporsi Buah:Air dan Buah Utuh serta Buah Kupas terhadap Rerata Total Asam pada Sari Buah Anggur Beralkohol 
Rerata total asam sari buah anggur beralkohol dari perlakuan proporsi buah:air dan buah utuh serta buah kupas berkisar antara 1,49-1,99\%. Hasil rerata total asam akibat faktor proporsi buah:air dan buah utuh serta buah kupas dapat dilihat pada Gambar 3.

Total asam mengalami peningkatan setelah proses fermentasi alkohol hal ini terjadi akibat perubahan komposisi kimia akibat fermentasi alkohol oleh Saccharomyces cerevisiae dimana gula yang ditambahkan akan diubah menghasilkan alkohol dan asam-asam organik. Hal ini juga ditambahkan menurut Daulay dan Rahman (1992), pada proses fermentasi minuman beralkohol, gula diubah menjadi alkohol, asam-asam organik, gliserol dan gas $\mathrm{CO}_{2}$.

\section{Aktivitas Antioksidan Sari Buah Anggur Bali Beralkohol}

Rerata aktivitas antioksidan pada sari buah anggur beralkohol berkisar antara 44,01-68,85\%. Pengaruh perubahan aktivitas antioksidan akibat faktor proporsi buah:air dan perlakuan buah utuh serta buah kupas ditunjukkan pada Gambar 4.

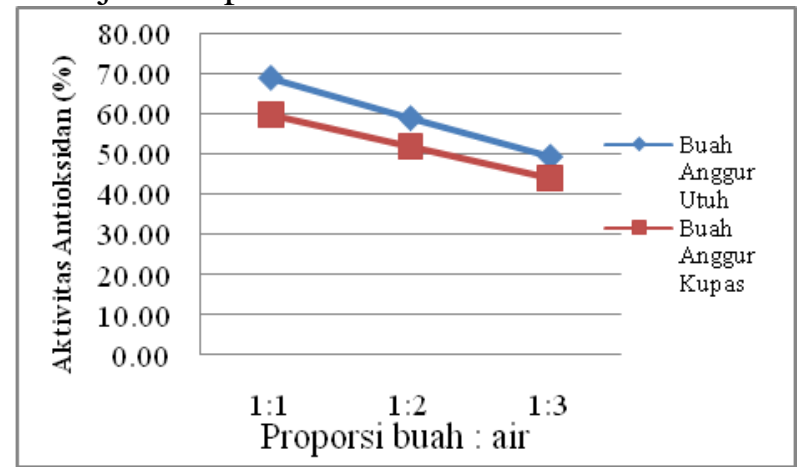

Gambar 4. Pengaruh Proporsi Buah : Air dan Perlakuan Buah Utuh serta Buah Kupas terhadap Rerata Aktivitas Antioksidan Sari Buah Anggur Beralkohol

Setelah menjadi sari buah beralkohol, aktivitas antioksidan pada berbagai proporsi buah:air mengalami penurunan karena dalam buah anggur banyak mengandung senyawa flavonoid yang merupakan antioksidan yang bersifat larut air. Hal ini didukung oleh pernyataan dari Harborne (1996) yang menyatakan bahwa flavonoid merupakan senyawa yang larut air dan pada proses pemanasan dapat menyebabkan senyawa antioksidan berkurang. Pada sari buah anggur beralkohol yang menggunakan buah utuh memiliki aktivitas antioksidan yang lebih tinggi daripada yang menggunakan buah kupas. Hal ini terjadi karena pada kulit buah anggur banyak terdapat kandungan antosianin yang merupakan senyawa antioksidan. Menurut Karyadi (2005), antosianin merupakan senyawa fitokimia yang memberikan warna ungu pada buah anggur. Menurut Espada (2004), kandungan antosianin dalam red wine sebesar 24-35 $\mathrm{mg} / 100 \mathrm{gr}$.

\section{Total Asam Cuka Anggur}

Total asam biasanya berbanding lurus dengan nilai $\mathrm{pH}$, semakin rendah nilai $\mathrm{pH}$ maka total asam akan semakin tinggi. Pada cuka buah anggur Bali dengan perlakuan buah utuh dan buah kupas serta proporsi buah:air memiliki nilai total asam berkisar antara 2,58 - 5,74\%. Pengaruh perlakuan buah utuh dan buah kupas serta proporsi buah:air terhadap rerata total asam cuka buah anggur Bali disajikan pada Gambar 5.

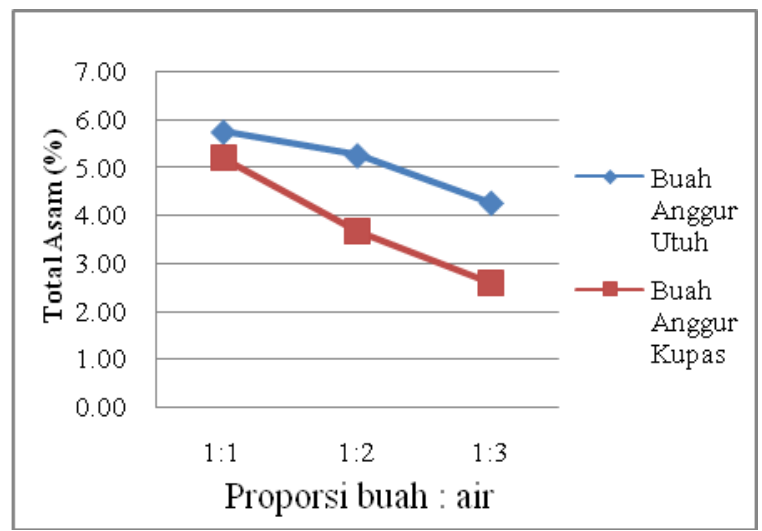

Gambar 5. Pengaruh Perlakuan Buah Utuh dan Buah Kupas serta Proporsi Buah : Air terhadap Rerata Total Asam Cuka Anggur Bali

Gambar 5 menunjukkan total asam tertinggi pada perlakuan buah utuh dengan proporsi buah : air 1:1. Seiring dengan meningkatnya proporsi air maka nilai total asam semakin menurun dan juga dengan buah utuh yang memiliki nilai total asam yang lebih tinggi dibandingkan buah kupas. Pada kulit buah anggur Bali mengandung senyawa derivat asam $\left(\right.$ Anonymous $\left.^{b}, 2011\right)$ dan menurut Chang (2005), asam yang 
umum red wine vinegar (cuka anggur dengan buah utuh) kaya akan asam tartarat, asam malat, dan asam laktat selain asam asetat. Menurut Bamforth (2005) Acetobacter akan mengoksidasi ethanol menjadi asam asetat, sehingga kadar ethanol dalam produk akan berkurang.

\section{Nilai pH Cuka Anggur}

Nilai pH merupakan ukuran yang menyatakan banyaknya ion $\mathrm{H}^{+}$pada media. Banyaknya ion $\mathrm{H}^{+}$terukur menunjukkan tingkat keasaman suatu bahan. Pengaruh perlakuan buah utuh dan buah kupas serta proporsi buah:air terhadap rerata $\mathrm{pH}$ cuka buah Anggur Bali dapat dilihat pada Gambar 6.

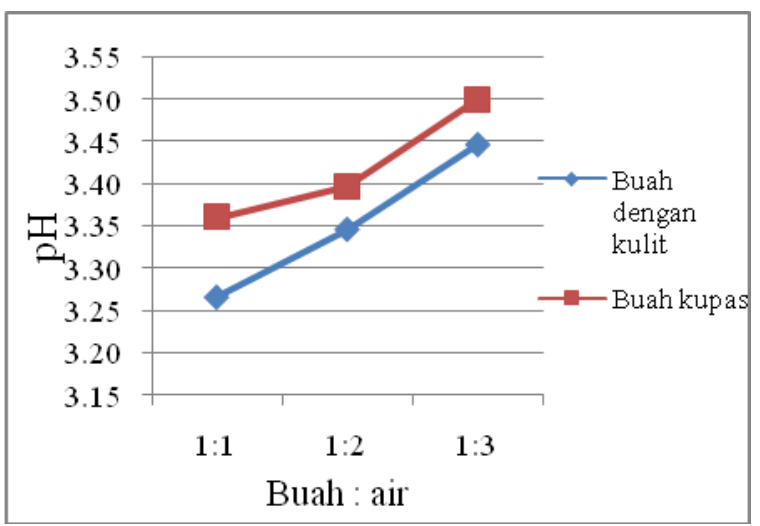

Gambar 6. Pengaruh Perlakuan Buah Utuh dan Buah Kupas serta Proporsi Buah : Air terhadap terhadap Rerata $\mathrm{pH}$ Cuka Anggur Bali

Gambar 6 menunjukkan bahwa nilai $\mathrm{pH}$ terendah ada pada perlakuan buah utuh dengan proporsi buah : air 1:1. pH sari buah anggur Bali beralkohol setelah fermentasi oleh Saccharomyces cerevisiae berkisar antara 3,53 - 3,69 sedangkan nilai $\mathrm{pH}$ sesudah fermentasi asetat menjadi berkisar antara 3,26 - 3,5. Nilai $\mathrm{pH}$ yang terukur dipengaruhi oleh jumlah asam asetat yang merupakan metabolit dari bakteri asam asetat yang digunakan. Penurunan $\mathrm{pH}$ ini disebabkan oleh ion $\mathrm{H}^{+}$yang dilepaskan dari asam asetat yang dihasilkan selama proses fermentasi asetat, sehinggga semakin tinggi asam asetat yang dihasilkan maka semakin rendah nilai $\mathrm{pH}$, sehingga cuka buah anggur Bali yang dihasilkan semakin asam. Menurut Naidu (2000), asam asetat yang terlarut akan berdisosiasi melepaskan proton-proton bebas yang menurunkan $\mathrm{pH}$ larutan.

\section{Kadar Alkohol Sisa}

Rerata kadar alkohol sisa pada berbagai proporsi buah:air dan perlakuan buah utuh serta buah kupas berkisar antara 2,11-2,41\%. Tabel 3 menunjukkan pengaruh berbagai proporsi buah:air dan perlakuan buah utuh serta buah kupas terhadap kadar alkohol cuka buah anggur Bali.

Tabel 3. Kadar Alkohol Sisa pada Cuka Anggur akibat Proporsi Buah:Air dan Perlakuan Buah Utuh serta Buah Kupas

\begin{tabular}{ccc}
\hline \multicolumn{2}{c}{ Perlakuan } & \multirow{2}{*}{ Kadar Alkohol } \\
\hline Buah & $\begin{array}{c}\text { Proporsi } \\
\text { Anggur }\end{array}$ & $\begin{array}{c}\text { Buah:Air } \\
\text { Bun }\end{array}$ \\
\hline \multirow{3}{*}{ Utuh } & $1: 1$ & 2,11 \\
\cline { 2 - 3 } & $1: 2$ & 2,21 \\
\cline { 2 - 3 } & $1: 3$ & 2,3 \\
\hline \multirow{3}{*}{ Kupas } & $1: 1$ & 2,17 \\
\cline { 2 - 3 } & $1: 2$ & 2,33 \\
\cline { 2 - 3 } & $1: 3$ & 2,41 \\
\hline
\end{tabular}

Tabel 3 menunjukkan bahwa kadar alkohol terendah didapatkan pada perlakuan proporsi buah:air 1:1 dengan perlakuan buah utuh. Persentase alkohol tersisa yang rendah menunjukkan bahwa lebih banyak alkohol yang dirombak oleh Acetobacter acetii menjadi asam asetat sebagai medium fermentasi asetat. Menurut Rahman (1989), alkohol merupakan sumber nutrisi bakteri asam asetat untuk hidup dan diubah menjadi asam asetat, sehinggga semakin besar asam asetat yang dihasilkan maka semakin sedikit alkohol yang tersisa.

\section{Total Gula Cuka Anggur}

Rerata total gula yang dihasilkan pada perlakuan buah utuh dan buah kupas serta berbagai proporsi buah:air berkisar antara $0,44 \%-0,94 \%$. Grafik Pengaruh perlakuan buah utuh dan buah kupas serta proporsi buah:air pada cuka anggur Bali dapat dilihat pada Gambar 7.

Gambar 7 menunjukkan semakin tinggi proporsi air, maka semakin rendah total gula sisa yang diperoleh. Perlakuan buah anggur utuh dengan proporsi buah:air 
1:1 memiliki nilai total gula tertinggi yaitu: $0,937 \%$. Dan nilai total gula terrendah pada perlakuan buah anggur kupas dengan proporsi buah:air 1:3 yaitu: 0,437\%. Menurut Chang (2005) total gula pada wine vinegar biasanya kurang dari $3 \%$. Selama fermentasi alkohol, khamir akan memecah gula (sukrosa) menjadi fruktosa dan glukosa. Glukosa digunakan oleh khamir menghasilkan etanol dan $\mathrm{CO}_{2}$. Glukosa juga digunakan bakteri asam asetat untuk mensintesa selulosa microbial (Fardiaz,1992).

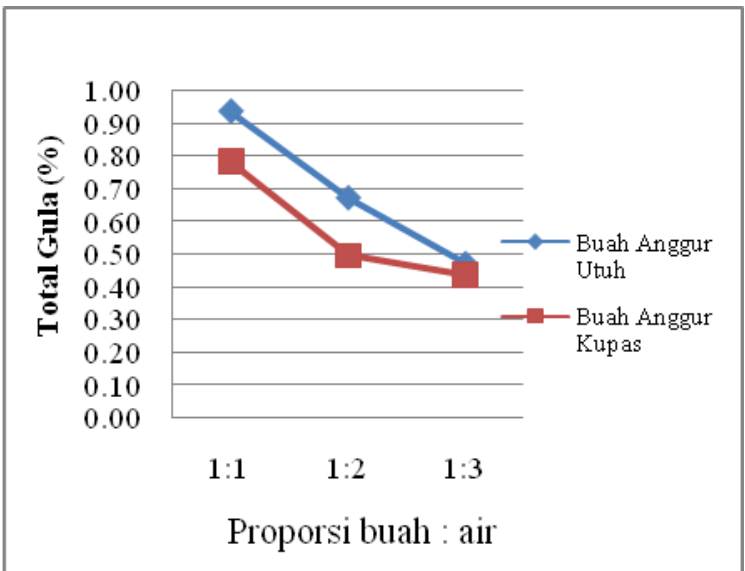

Gambar 7. Pengaruh Perlakuan Buah Utuh dan Buah Kupas serta Proporsi Buah : Air terhadap Rerata Total Gula Cuka Anggur Bali

\section{Aktivitas Antioksidan Cuka Anggur}

Rerata hasil analisa aktivitas antioksidan pada cuka anggur Bali dengan berbagai proposi buah:air dan perlakuan buah utuh serta buah kupas berkisar antara 25,05\%-59,49\%. Pengaruh proporsi buah:air dan perlakuan buah utuh serta buah kupas terhadap aktivitas antioksidan cuka anggur Bali disajikan pada Gambar 8.

Aktivitas antioksidan pada cuka anggur lebih rendah jika dibandingkan dengan sari buah anggur dan sari buah anggur beralkohol. Hal tersebut berbanding lurus dengan penurunan total fenol pada cuka anggur Bali. Rerata total fenol pada sari buah anggur dengan berbagai macam proporsi buah : air dan perlakuan buah utuh serta buah kupas pada awalnya berkisar antara 482,56 ppm-632,23ppm. Setelah menjadi cuka total fenol mengalami penurunan menjadi 276,03ppm-423,27ppm. Penurunan aktivitas antioksidan selama fermentasi diduga disebabkan adanya aerasi pada fermentasi asetat sehingga senyawa seperti vitamin $\mathrm{C}$, senyawa flavonoid dan polifenol dalam buah anggur mengalami oksidasi. Sebagian besar penurunan senyawa antioksidan diakibatkan oleh oksigen dan panas akibat pasteurisasi (Prakash, 2001). Hal tersebut juga didukung oleh Handayani (2008) yang menyatakan bahwa senyawa flavonoid tidak stabil terhadap perubahan pengaruh oksidasi, cahaya dan perubahan kimia.

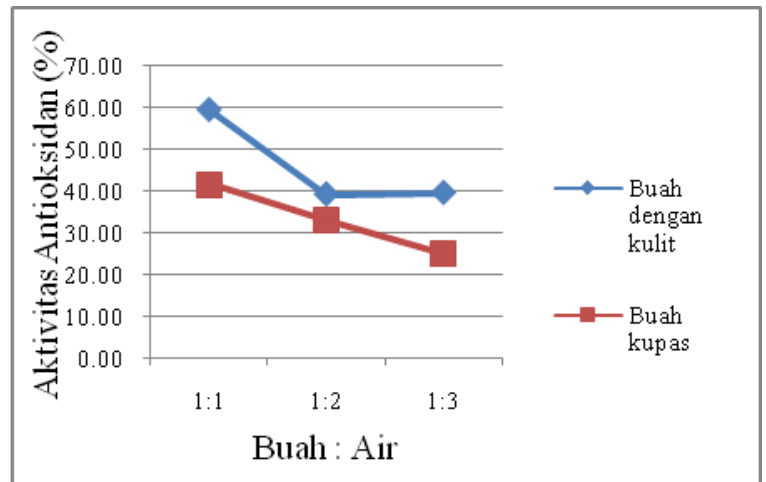

Gambar 8. Pengaruh Perlakuan Buah Utuh dan Buah Kupas serta Proporsi Buah : Air terhadap Rerata Aktivitas Antioksidan Cuka Anggur Bali

\section{Pemilihan Perlakuan Terbaik}

Pemilihan perlakuan terbaik untuk hasil penelitian ini menggunakan metode Zeleny yang dilakukan pada produk akhir cuka dengan parameter nilai total asam tertinggi, $\mathrm{pH}$ terendah, dan aktivitas antioksidan tertinggi. Cuka anggur Bali dengan perlakuan proporsi buah:air 1:1 dan menggunakan buah anggur utuh merupakan perlakuan terbaik. Hasil perlakuan terbaik memiliki karakteristik kimia seperti total asam 5,74\%, pH 3,27, dan aktivitas antioksidan 59,49\%.

\section{KESIMPULAN}

Buah anggur merupakan buah yang banyak mengandung senyawa flavonid, polifenol dan vitamin $\mathrm{C}$ yang berpotensi sebagai antioksidan. Oleh karena itu buah anggur dapat diaplikasikan ke dalam produk pangan fungsional seperti cuka buah. Cuka anggur Bali dengan perlakuan proporsi 
buah:air 1:1 dan menggunakan buah anggur utuh merupakan perlakuan terbaik. Hasil perlakuan terbaik memiliki karakteristik kimia seperti total asam 5,74\%, pH 3,27, dan aktivitas antioksidan $59,49 \%$.

\section{DAFTAR PUSTAKA}

Anonymous. $2010^{\mathrm{a}}$. Khasiat Buah Anggur. http://mediapenunjangmedis.dikirismant o.com/khasiat-buah-anggur.html 2010. diakses tanggal 5 Maret 2012.

Anonymous.2011 ${ }^{\mathrm{b}}$ Anggur Bali. http://dencarik.blogspot.com/2011/06/an ggur-bali-adalah-anggur-untukwine.html. diakses tanggal 5 Maret $\underline{2012}$.

Anugoro, Dito.2011. Anggur: Antioksidan Antikanker Alami. www.detkhealth.com. diakses 20 April 2012.

Bamforth, C.W.2005. Food, Fermentation and Micro-organism.Newgen Imaging System (P) Ltd, Chennai. British.

Chang, Rei-Chu, Lee Hsiu-Chin, and Andi Shau-Mei. 2005. Investigation of the Physicochemical Properties of Concentrated Fruit Vinegar. Journal of Food and Drug Analysis, 13, No. 4, Pages 348-356.

Cirlini, Martina. 2008. Development of New Analytical Methods for the Characterization, Authentication and Quality Evaluation of Balsamic Vinegar of Modena. Universita' Delgi Studi Di Parma.Facolta' Di Agraria.

Daulay, D dan A. Rahman. 1992. Teknologi Fermentasi Sayuran dan Buah - Buahan. PAU Pangan dan Gizi. Bogor.

Espada,A.C. 2004. Anthocyanin Quantification and Radical Scavenging Capacity of Concord, Norton, and Marechal Foch Grapes and Wines. Journal of Agricultural and Food Chemistry 52 (22): 6779-86.

Fardiaz, S. 1992. Mikrobiologi Pangan. PT. Gramedia Pustaka Utama. Jakarta.
Biochemistry of Plants, Vol. 7: Secondary Plant Products. New York: Academic Press.

Handayani, R.2008. Sintesis Senyawa Flavonoid- $\alpha$-Glikosida secara Reaksi Transglikosilasi Enzimatik dan Aktivitasnya sebagai Antioksidan. Bidang Mikrobiologi,Pusat Penelitian Biologi, Lembaga Ilmu Pengetahuan Indonesia (LIPI). Cibinong-Bogor.

Harborne, J.B. 1996. Metode Fitokimia. Penerbit ITB. Bandung.

Karyadi, E. 2005. Antioksidan Resep Sehat dan Umur Panjang.

http://www.indomedia.com. Diakses tanggal 2 Desember 2012.

Maharani,D.M.2011. Produksi Etanol dari Ubi Kayu. repository.ipb.ac.id/.../BAB\%20IV\%2OH asil\%20dan\%20Pembahasan. Diakses tanggal 2 November 2012.

Naidu, A.S. 2000. Natural Food Antimicrobial Systems. CRC Press. New York.

Pragana. 2010.2 Cuka. http://anandagagan.blogspot.com/2010/0 3/cuka.html. diakses tanggal 5 April 2012.

Prakash, A. 2001. Antioxidant Activity. Medallion Laboratories Analytical Progress Vol. 19 No. 2. Minnesota.

Rahman, A. 1989. Pengantar Teknologi Fermentasi. Pusat Antar Universitas Pangan dan Gizi IPB. Bogor.

Wigyanto, N. 2001. Peningkatan Efisiensi Produksi Asam Asetat Menggunakan Kolom Bertingkat. Jurnal Universitas Brawijaya 7(2): 49-57.

Wood, B.J.B. 1998. Microbiology of Fermented Food. Blackie Academic and Professional. London. United Kingdom.

Yatni, N.2008. Penentuan Mutu Cuka Nira Aren (Arenga pinnata) berdasarkan SNI 01-4371-1996. Jurnal Perennial, 5(1) : 31-35.

Hahlbrock K. 1981. Flavonoids. dalam The 
Zubaidah, E. 2010. Kajian Perbedaan Kondisi Fermentasi Alkohol dan Konsentrasi Inokulum pada Pembuatan Cuka Salak (Salacca zalacca). Jurnal Teknologi Pertanian Vol. 11 No. 2 (Agustus 2010) 